\title{
IL-1 signaling mediates intrauterine inflammation and chorio-decidua neutrophil recruitment and activation
}

\author{
Pietro Presicce, ${ }^{1}$ Chan-Wook Park, ${ }^{1}$ Paranthaman Senthamaraikannan, ${ }^{1}$ Sandip Bhattacharyya, ${ }^{2}$ \\ Courtney Jackson, ${ }^{3}$ Fansheng Kong, ${ }^{2}$ Cesar M. Rueda, ${ }^{3}$ Emily DeFranco, ${ }^{4}$ Lisa A. Miller, ${ }^{5}$ \\ David A. Hildeman, ${ }^{3}$ Nathan Salomonis, ${ }^{6}$ Claire A. Chougnet, ${ }^{3}$ Alan H. Jobe, ${ }^{1}$ and Suhas G. Kallapur ${ }^{1}$ \\ 'Division of Neonatology/Pulmonary Biology, ${ }^{2}$ Division of Human Genetics, and ${ }^{3}$ Division of Immunobiology, Cincinnati \\ Children's Hospital Research Foundation, University of Cincinnati College of Medicine, Cincinnati, Ohio, USA. \\ ${ }^{4}$ Department of Obstetrics/Gynecology, Maternal-Fetal Medicine, University of Cincinnati, Cincinnati, Ohio. \\ ${ }^{5}$ California National Primate Research Center, Department of Anatomy, Physiology, and Cell Biology, School of Veterinary \\ Medicine, UCD, Davis, California, USA. ${ }^{6}$ Division of Biomedical informatics, Cincinnati Children's Hospital Research \\ Foundation, Cincinnati, Ohio, USA.
}

Neutrophil infiltration of the chorioamnion-decidua tissue at the maternal-fetal interface (chorioamnionitis) is a leading cause of prematurity, fetal inflammation, and perinatal mortality. We induced chorioamnionitis in preterm rhesus macaques by intraamniotic injection of LPS. Here, we show that, during chorioamnionitis, the amnion upregulated phospho-IRAK1expressed neutrophil chemoattractants CXCL8 and CSF3 in an IL-1-dependent manner. IL-1R blockade decreased chorio-decidua neutrophil accumulation, neutrophil activation, and IL-6 and prostaglandin E2 concentrations in the amniotic fluid. Neutrophils accumulating in the choriodecidua had increased survival mediated by BCL2A1, and IL-1R blockade also decreased BCL2A1+ chorio-decidua neutrophils. Readouts for inflammation in a cohort of women with preterm delivery and chorioamnionitis were similar to findings in the rhesus macaques. IL- 1 is a potential therapeutic target for chorioamnionitis and associated morbidities.

Authorship note: PP and CWP contributed equally to this manuscript.

Conflict of interest: The authors have declared that no conflict of interest exists.

Submitted: October 25, 2017 Accepted: February 13, 2018 Published: March 22, 2018

\section{Reference information:} JCI Insight. 2018;3(6):e98306. https://doi.org/10.1172/jici. insight.98306.

\section{Introduction}

Perinatal infections are a significant cause of prematurity and perinatal mortality, which are important indicators of societal health (1). Currently, the rate of prematurity remains high at about $10 \%$ of all US births (2). Globally, about 1 million deaths/year are attributable to prematurity $(3,4)$. Intrauterine infection/inflammation (IUI) is associated with $\sim 40 \%$ of premature deliveries $(5,6)$. IUI also increases the risk for fetal and newborn brain injury (7), necrotizing enterocolitis (8), and chronic lung disease (9). The histologic correlate of IUI is chorioamnionitis, defined as neutrophil infiltration of maternal-fetal membranes and the placenta (10). The products of inflammation during IUI are strongly implicated as causative agents of prematurity (11).

Neutrophil infiltration at the maternal-fetal interface occurs in the chorioamnion-decidua (chorio-decidua) space, amniotic fluid (AF), and fetal tissues. Neutrophils in the chorio-decidua are largely of maternal origin (12), while neutrophils in the AF are largely of fetal origin (13). Mechanisms of how neutrophils accumulate in different maternal-fetal niches are poorly understood. Activated tissue neutrophils are known to survive longer compared with blood neutrophils (14), but neutrophil survival at the maternal-fetal interface has not been evaluated. Whether neutrophils are critical regulators of maternal-fetal inflammation and preterm labor (PTL) remains unclear (15-19).

IL-1 $\beta$ is implicated in the pathogenesis of IUI-mediated PTL in the rhesus $(20-22)$, mouse $(23,24)$, and humans (25-28). We therefore hypothesized that IL-1 $\beta$ regulates neutrophil accumulation and activation at the maternal-fetal interface. Given the close similarities between the rhesus macaques and humans in reproductive biology and placenta/fetal immunology $(29,30)$, we induced chorioamnionitis in rhesus macaques by intraamniotic (IA) injection of LPS (31). We used the clinical preparation of human recombinant IL-1 receptor antagonist (rhIL-1ra, Anakinra) to inhibit both IL-1 $\alpha$ and IL-1 $\beta$ signaling $(32,33)$. We also recruited a cohort of women delivering preterm with and without chorioamnionitis and analyzed their placental 
inflammation. We report the effects of IL-1 blockade of LPS signaling at the maternal-fetal interface in the rhesus given IA LPS. Additionally, we report very similar cellular inflammation response in the rhesus macaques and humans during chorioamnionitis.

\section{Results}

Human and rhesus chorioamnionitis have similar inflammation readouts. We compared intrauterine inflammation in rhesus macaques delivered at $80 \%$ gestation $(n=13)$ with a cohort of women delivering at $\sim 32$ weeks of gestation $(n=30)$. Human cohorts were developed based on histologically diagnosed chorioamnionitis (clinical details are given in Supplemental Tables 1 and 2; supplemental material available online with this article; https://doi.org/10.1172/jci.insight.98306DS1). In both the rhesus and human chorio-decidua, NK cells, macrophages, and $\mathrm{T}$ cells were the most abundant leukocytes at baseline (Figure 1A and Supplemental Figure 1). In contrast, neutrophils became the most abundant leukocytes during chorioamnionitis (Figure 1A). Neutrophils identified by morphology (Figure 1B) and by neutrophil elastase staining (Supplemental Figure 2) were primarily located at the chorio-decidua interface in both the rhesus and human tissues. The mRNA profile and magnitude of induction of several pro- and antiinflammatory mediators were similar in the rhesus and humans (Figure 1C). These data demonstrate similarities between rhesus and human chorioamnionitis.

IA LPS causes a time-dependent inflammation at the maternal-fetal interface. To understand the progression of inflammation, we surgically delivered rhesus macaques 16 hours or 48 hours after IA LPS. IA LPS increased expression of IL6,IL8/CXCL8,IL1B, TNFA, and MCP1/CCL2 mRNAs in the chorio-decidua (Supplemental Figure 3). Since most inflammatory markers were higher at 16 hours compared with 48 hours, we used this time point for subsequent studies.

rhIL-1 ra blocks activation of IRAK1 and expression of neutrophil chemoattractants in the amnion. To determine the role of IL-1 signaling, we injected Anakinra (rhIL-1ra) in the AF and s.c. tissue of the dams (Supplemental Figure 4A). S.c. rhIL-1ra crossed the amniotic epithelial barrier minimally $(0.2 \%$ diffusion from blood to AF) (Supplemental Figure 4B). rhIL-1ra elimination was slower in the AF compared with maternal blood. Importantly, the maternal plasma concentrations of Anakinra were comparable with Anakinra plasma concentrations in patients treated for IL-1-mediated neonatal-onset multisystem disease in whom the drug had efficacy $(34,35)$. The AF levels were about 20-fold higher.

As the amnion is in contact with AF, it is strategically located to transduce inflammatory signals in the AF to recruit neutrophils to the chorio-decidua. The abundance of phospho-IRAK1 (pIRAK1), a key mediator of TLR signaling (36), was selectively induced in the amnion from the LPS-exposed rhesus (Figure 2A; see complete unedited blots in the supplemental material). rhIL-1ra effectively decreased expression of pIRAK1, IL1B, CSF3, CXCL8, and IL6 in the amnion from IA LPS-exposed rhesus (Figure 2B). In clinical situations, inflammatory signals may come from the AF (inside-out signals) or from decidua (outside-in signals). In the amnion from subjects with chorioamnionitis, pIRAK1 abundance and expression of CSF3, CXCL8/IL8, IL6, and IL1B selectively increased compared with tissue from subjects without chorioamnionitis (Figure 2, C and D). Thus, amnion expression of neutrophil chemoattractants appears to be a general phenomenon during chorioamnionitis. Figure $2 \mathrm{E}$ shows a model demonstrating IL-1 $\beta$ downstream of TLR and CXCL8/CSF3 downstream of IL-1R in the amnion.

rhIL-1ra blocks neutrophil accumulation in chorio-decidua. The frequency and numbers of neutrophils increased in the chorio-decidua ( 37-fold) after IA LPS injection (Figure 3, A and B, respectively). rhIL1ra decreased the neutrophil accumulation in the chorio-decidua by $>90 \%$. Overall chorio-decidua $\mathrm{CD}_{4} 5^{+}$ cell counts increased $\sim 4$.5-fold upon IA LPS injection, with little change in the CD45- cell counts (data not shown). rhIL-1 ra decreased overall chorio-decidua leukocyte counts (data not shown). In contrast to neutrophils, IA LPS did not significantly change the number of chorio-decidua NK cells, NKT cells, conventional $\mathrm{CD}^{+} \mathrm{T}$ cells (Conv T), or Tregs. IA LPS slightly increased the number of macrophages and B cells ( 2fold and $\sim 1.5$-fold, respectively) (Supplemental Figure 5). Interestingly, rhIL-1ra also decreased LPS-induced increases in monocyte/macrophage and B cell numbers to control levels (Supplemental Figure 5).

rhIL-1ra blocks chorio-decidua neutrophil activation. Among chorio-decidual cells, neutrophils were the major producers of TNF- $\alpha$ after IA LPS (data not shown). IA LPS increased the frequency of TNF- $\alpha^{+}$chorio-decidua neutrophils, which was reversed by rhIL-1ra (Figure 4A). rhIL-1ra also decreased IA LPS-induced $\mathrm{CXCL}^{+}$cells in the chorio-decidua identified as neutrophils based on neutrophil elastase costaining (Figure 4, B-E). IA LPS increased both CD16 (FcRIII) (Figure 4F) and CD63 (marker for release of azurophilic granules) (Figure 4G) expressing chorio-decidua neutrophils. There was a nonsignificant trend for rhIL-1ra 
A

Pre-term chorio-decidua leukocytes

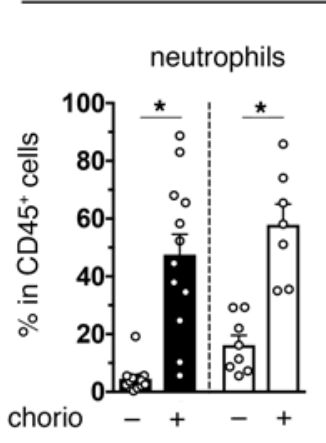

B

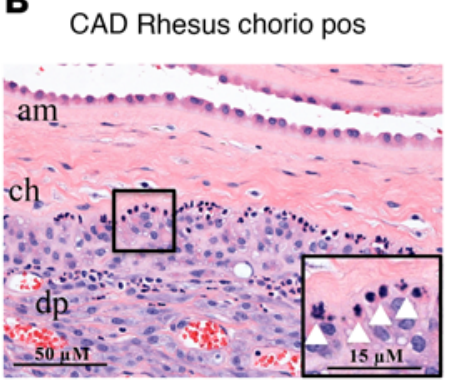

CAD Human chorio pos

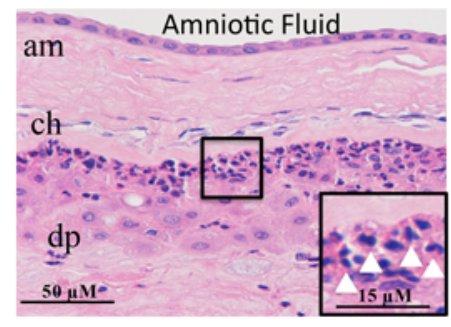

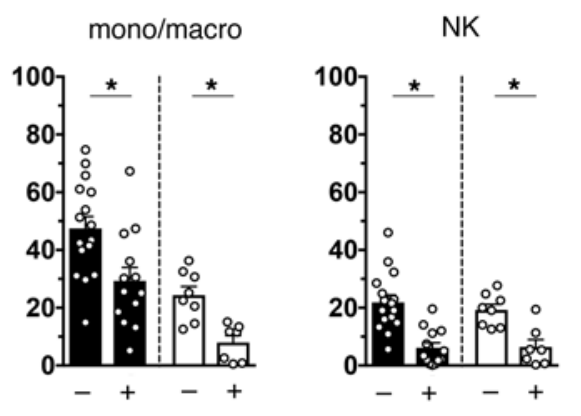
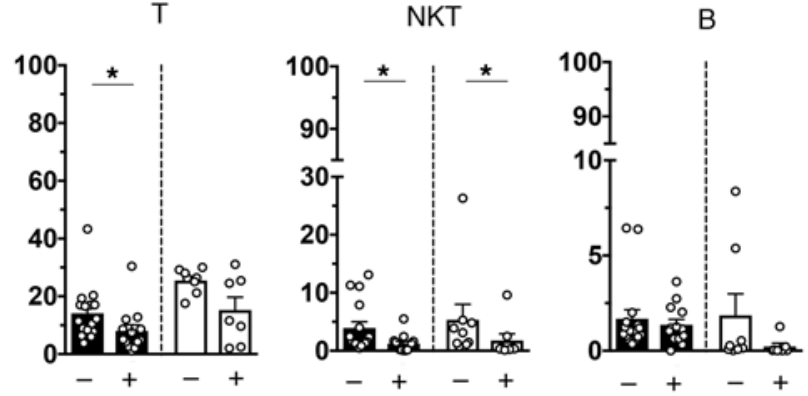

Rhesus $\square$ Human

C

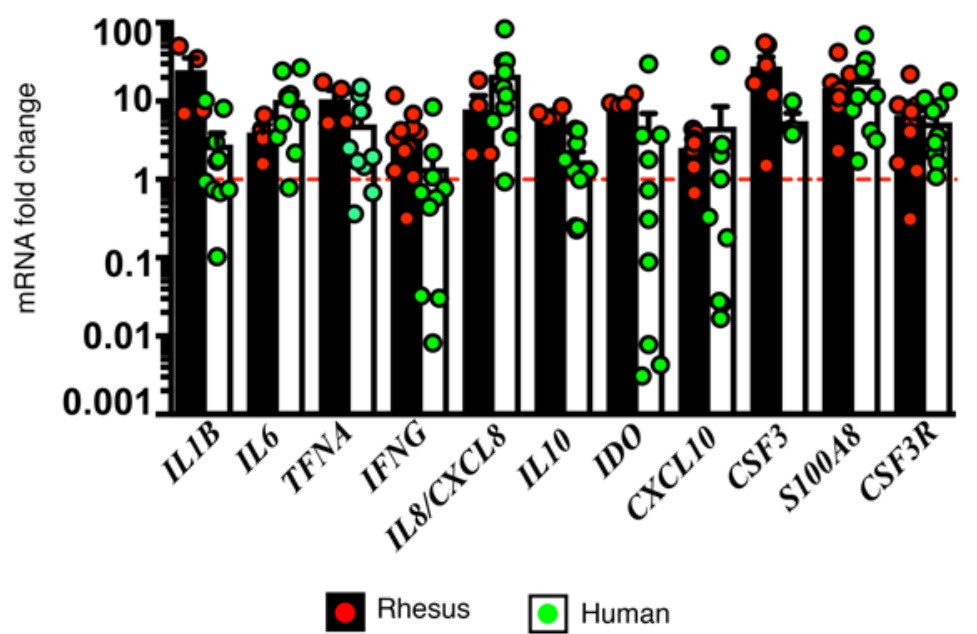

Figure 1. Close similarities between rhesus intrauterine inflammation and human chorioamnionitis (chorio). Chorio was induced in rhesus macaques by intraamniotic (IA) LPS at 80\% gestation with delivery 16 hours later. Samples were collected immediately after birth from women delivering preterm, and chorioamnionitis was diagnosed by placenta histology. (A) Chorio-decidua cells were scraped and digested with protease/DNAase, and single cell suspensions were used for multiparameter flow cytometry phenotyping (rhesus chorio neg., $n=16$; rhesus chorio pos., $n=13$; human chorio neg., $n=8$; human chorio pos., $n=7$ ). Note the close similarities in proportions of $\mathrm{CD} 45^{+}$subsets in rhesus vs. human neutrophil predominance in chorio pos. groups. Data are mean $\pm \mathrm{SEM},{ }^{*} P<0.05$ between comparators by Mann-Whitney test. (B) Representative fetal membrane (chorioamnion-decidua, CAD; $n=5$ ) H\&E histology. Note the neutrophil infiltration at the chorio-decidua interface (white arrowheads) in both rhesus and human chorio (am, amnion; ch, chorion; dp, decidua parietalis). (C) Expression of mRNAs by quantitative PCR (Taqman probes) in the fetal membranes during chorio (rhesus chorio pos., $n=$ 4-10; human chorio pos., $n=4-11$ ). Average mRNA values are fold increases over the average value for control or no chorio (red dashed line) after internally normalizing to the housekeeping 18S RNA. Expression of many genes were similar in the rhesus and humans.

to decrease CD16 (Figure 4F). rhIL-1ra reversed the LPS-induced increase in neutrophil CD63 expression to near control levels (Figure 4G $[P=0.033]$ and Supplemental Figure 6). CD63 expression highly correlated with TNF- $\alpha$ expression in LPS-exposed neutrophils $\left(r^{2}=0.69, P=0.03\right.$, Figure $\left.4 \mathrm{H}\right)$. Interestingly, human chorio-decidua neutrophils from cases with chorioamnionitis had increased CD63 expression compared with chorio-decidua neutrophils from subjects without chorioamnionitis (Supplemental Figure 7).

IA LPS induced a chorio-decidua neutrophil prosurvival program mediated by BCL2A1. To understand transcriptomic changes, we analyzed highly upregulated genes in the maternal-fetal membranes during chorioamnionitis. The most upregulated genes in both rhesus and human chorio-decidua identified a profile of genes known to be expressed by activated neutrophils (Table 1). BCL2A1 (called BFL1 in humans), an inhibitor of apoptosis (37), is one of the highly upregulated genes common to both rhesus and humans. 
Rhesus Amnion

A
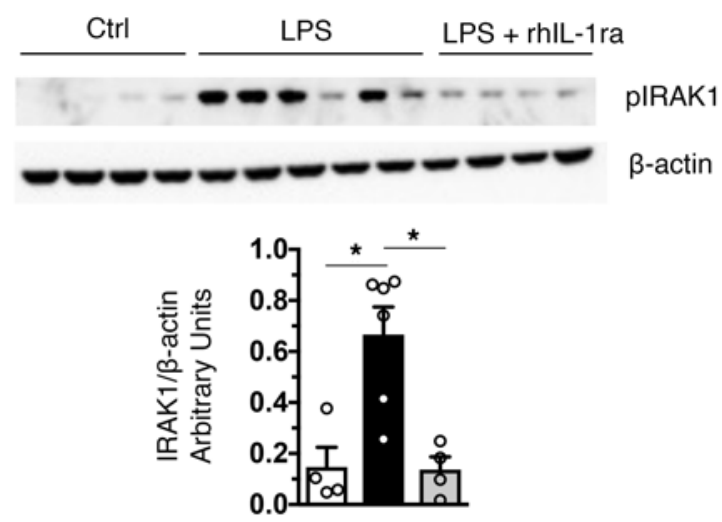

$\square$ Ctrl $\square$ LPS $\square$ LPS + rhlL-1ra

B

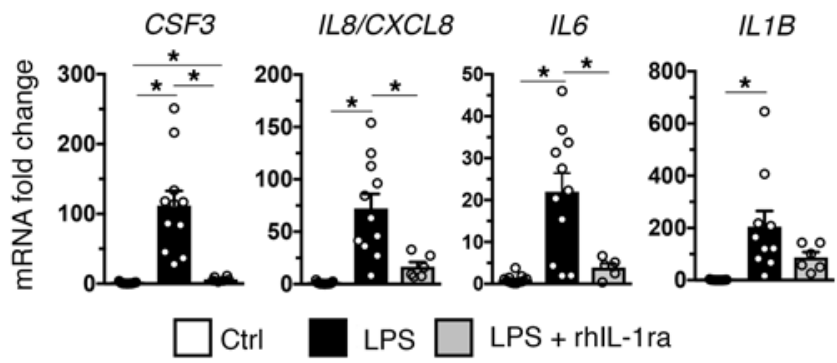

E

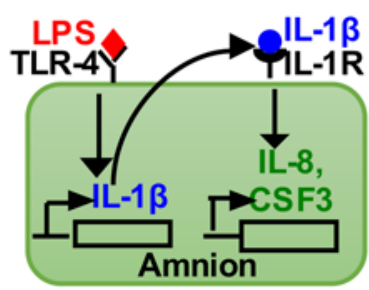

Human Amnion

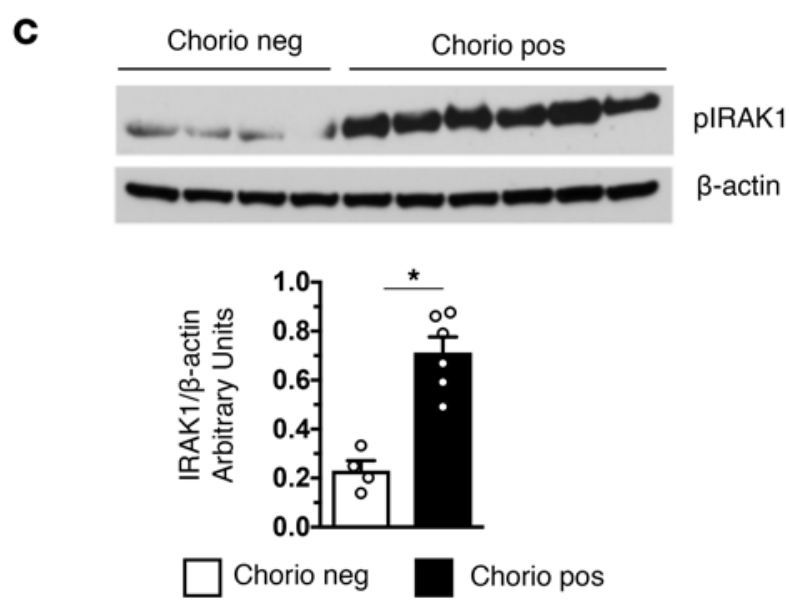

D

Figure 2. Activation of IRAK1 and induction of neutrophil chemoattractants is IL-1 dependent in the amnion. Amnion was physically separated from chorion and decidua immediately after birth from rhesus and humans delivering preterm. (A) Representative immunoblots of rhesus amnion ( $n=5)$ probed with antiphospho-IRAK1 and $\beta$-actin and quantification of IRAK1 expression (Ctrl, $n=4$; LPS, $n=6$; LPS + rhIL-1ra, $n=4$ ) are shown. (B) Expression of IA LPS-induced CSF3, IL8/CXCL8, and IL6 but not IL1 $\beta$ mRNA were inhibited by rhIL-1ra (Ctrl, $n=13$; LPS, $n=11$; LPS + rhIL-1ra, $n=6$ ). (C) Representative immunoblots of human amnion $(n=5)$ probed with anti-phospho-IRAK1 and $\beta$-actin and quantification of IRAK1 expression (Chorio neg., $n=4$; Chorio pos., $n=6$ ) are shown. (D) CSF3, IL8, IL6, and IL1 $\beta$ mRNAs increased in human chorio cases (Chorio neg., $n=16$; Chorio pos., $n=11$ ). (E) Model demonstrating IL-1 $\beta$ downstream of TLR and $\mathrm{CXCL8/CSF3}$ downstream of IL-1R in the amnion. Data are mean $\pm \mathrm{SEM},{ }^{*} P<0.05$ between comparators by Mann-Whitney test.

rhIL-1ra reversed the increased chorio-decidua expression of BCL2A1 in LPS-exposed animals (Figure 5A). Importantly, BCL2A1 was specifically expressed by chorio-decidua neutrophils, and rhIL-1ra decreased BCL2A1 ${ }^{+}$neutrophils (Figure 5, B-E).

Neutrophil expression of $B C L 2 A 1$ could be constitutive or induced. Thus, an increase in BCL2A1 in the chorio-decidua could be due to influx of neutrophils rather than transcriptional induction of the gene in the neutrophils. Since control chorio-decidua tissue has very few neutrophils, we compared expression of BCL2A1 and other important mediators of apoptosis in chorio-decidua neutrophils vs. blood neutrophils from the same IA LPS-exposed animals. Among antiapoptosis mediators, the expression of $B C L 2 A 1$ and $B C L X L$ was higher, but $B C L 2$ and $M C L 1$ expression did not change in chorio-decidua neutrophils (Figure $5 \mathrm{~F}$ ). The expression of proapoptotic mediators $B A D$ and $B A X$ did not change in chorio-decidua neutrophils, although we may have been limited with few samples for definitive determinations (Figure $5 \mathrm{~F}$ ). 


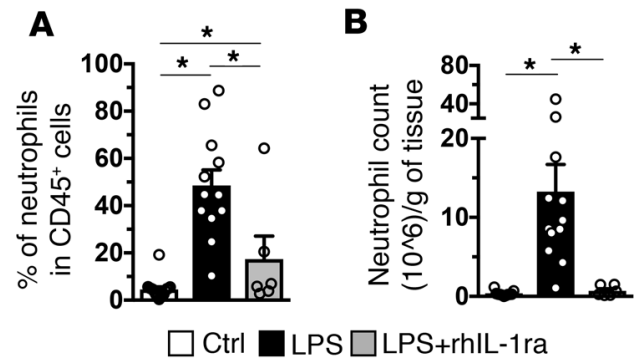

Figure 3. Neutrophil recruitment to the chorio-decidua after IA LPS exposure is significantly decreased by IL-1R blockade. Chorio-decidua cell suspensions were analyzed by multiparameter flow cytometry. IA LPS exposure increased significantly the frequency (Ctrl, $n=16$; LPS, $n$ $=12 ;$ LPS + rhlL-1ra, $n=6)(\mathbf{A})$ and the number (Ctrl, $n=$ 11; LPS, $n=12$; LPS + rhIL-1ra, $n=6$ ) (B) of chorio-decidua neutrophils compared with the control animals, and rhIL1ra injection reverted both frequency and counts to near control levels. Data are mean $\pm \mathrm{SEM},{ }^{*} P<0.05$ between comparators by Mann-Whitney test.

Since chorio-decidua in control rhesus macaques have very few neutrophils, we used blood neutrophils for comparative survival studies. Compared with blood neutrophils survival (45\% $\pm 5 \%, n=10)$ after 16 hours culture, chorio-decidua neutrophil survival was $86 \% \pm 3 \%(n=13)(P<0.05)$. Furthermore, decidua neutrophil survival was maintained over 72 hours in culture (Supplemental Figure 8 ). We also confirmed an increased expression of BCL2A1 in human chorio-decidua neutrophils compared with blood neutrophils (with the caveat that the source of blood neutrophils was from nonpregnant women) (Supplemental Figure 9). We next used pharmacological inhibition of the BCL2 family to determine the contribution of BCL2A1 in neutrophil survival in rhesus macaques. Consistent with the expression data, an inhibition of BCL2A1 (using ML214) (38) was more potent at decreasing neutrophil survival compared with inhibition of BCL2 (using ABT-737, which does not inhibit BCL2A1; ref. 39) (Figure 5G and Supplemental Figure 10). These data demonstrate that BCL2A1 is critical in mediating chorio-decidua neutrophil survival.

rhIL-1ra reduced IA LPS-induced intrauterine inflammation. NK cells, macrophages, T cells, and decidua stroma cells that are abundant in third-trimester primate decidua can potentially cause intrauterine inflammation without contributions from neutrophils (19). Validated biomarkers of inflammation-induced PTL include AF concentrations of prostaglandins (PG) and IL-6 $(40,41)$. rhIL-1ra significantly decreased LPS-induced AF concentrations of IL-6, CXCL8, MCP1, and PGE2, but not PGF2a or TNF- $\alpha$ concentrations (Figure 6A). AF neutrophil numbers were variable in both IA LPS and IA LPS + rhIL-1ra groups (Figure 6B). In contrast to large increases of cytokines in the AF, LPS exposure did not increase proinflammatory cytokine levels in the maternal plasma (Figure 6C). The fetal plasma cytokines increased slightly but significantly (Figure 6C). There were nonsignficant trends toward decreases in IL-6, IL-8/CXCL8, and CCL2/MCP1, but not TNF- $\alpha$ in fetal plasma upon rhIL-1ra treatment.

\section{Discussion}

IUI poses a challenge in balancing tolerogenic environment at the maternal-fetal interface, with a need for innate host defense. That preterm delivery may occur in association with leukocytosis of the AF or chorioamnion has long been recognized (42). Using a nonhuman primate model with close similarities to human chorioamnionitis, we show that IL-1 signaling mediates accumulation and activation of neutrophils at the maternal-fetal interface. IL-1 blockade decreased concentrations of proinflammatory mediators associated with PTL/delivery at the maternal-fetal interface $(41,43,44)$. Although some elements of the inflammation cascade have not been formally proven, our findings are consistent with the hypothesis that, during IUI, proinflammatory mediators signal the amnion tissue to secrete neutrophil chemoattractants with activation of the IRAK1 pathway. The neutrophil infiltration amplifies the inflammation at the maternal-fetal interface (Figure 7). Specific activation of the IRAK/NFאB/CXCL8 axis in the amnion in PTL but not preterm-no labor or term-labor cases has been recently reported (45).

IL-1 blockade decreased inflammation-induced PTL in some studies using rodent species $(24,46,47)$ but not in others (48). Our focus in the present study was to identify proximal mechanisms of intrauterine inflammation that may lead to PTL. In chronically catheterized rhesus macaques, PTL was reported with IA IL-1 $\beta$ or LPS within 3-day exposure $(49,50)$, while PTL did not occur with IA IL-1 $\beta$ exposure for 3 days in noninstrumented rhesus macaques (51). Even with inoculation of infectious agents in the nonhuman primates, there is variability in the incidence of PTL based on microbial virulence factors or the anatomical location of the infectious agent (e.g., chorio-decidua vs. AF) $(52,53)$. Thus, the PTL phenotype appears to be modulated by host-microbial interactions, spatial localization within the intrauterine space, and characteristics of the host inflammatory response. Mice lacking the IL-1 type I receptor are able to sense systemic LPS and mount 
A
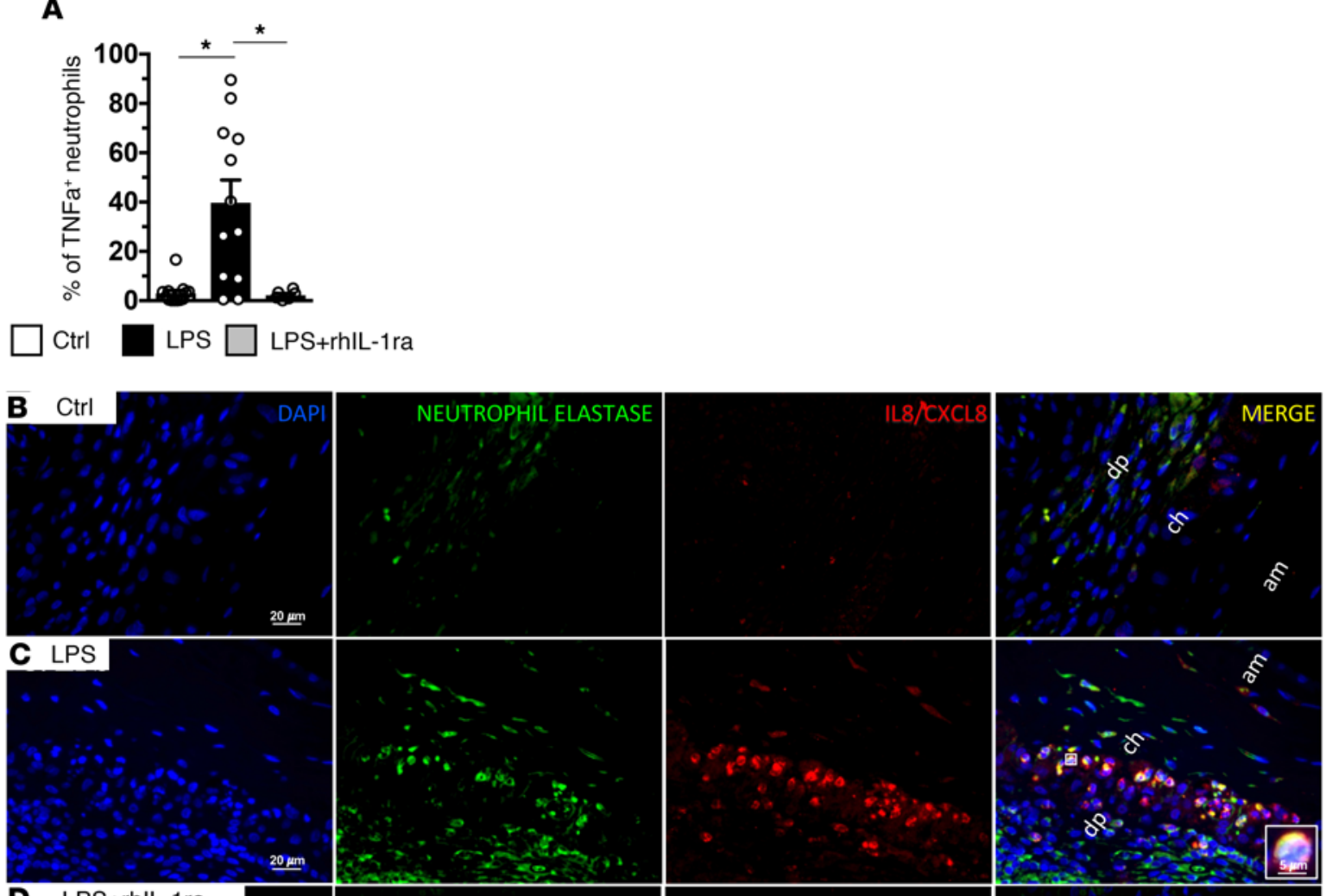

D LPS+rhlL-1ra
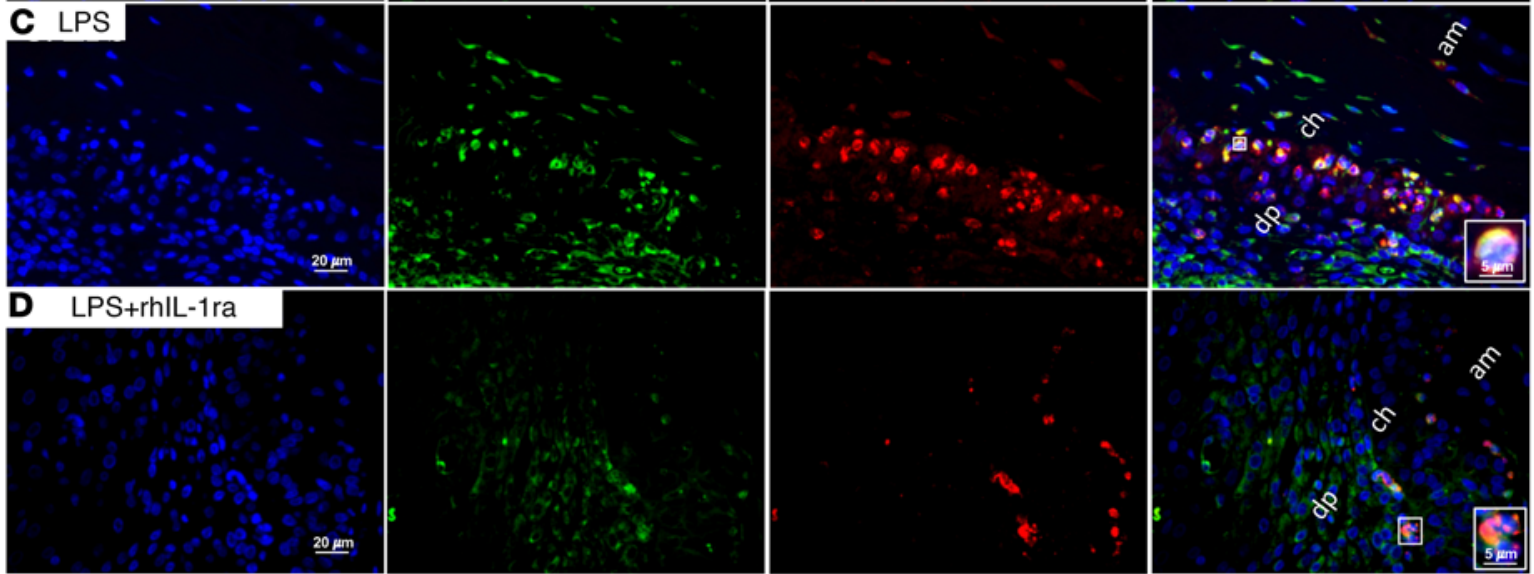

\section{E}

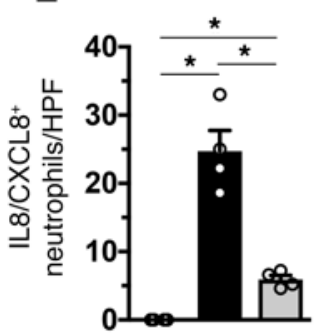

$\mathbf{F}$

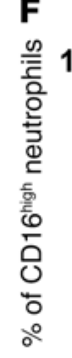

G

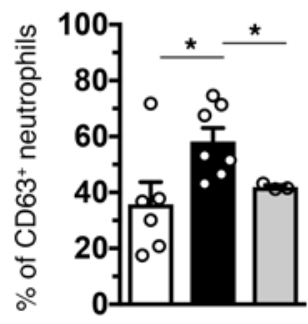

H

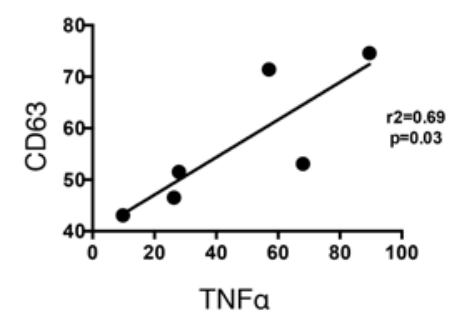

$\square$ Ctrl $\square$ LPS $\square$ LPS+rhlL-1ra

Figure 4. IA LPS induced chorio-decidua neutrophil cytokine production, and activation is IL-1 dependent. (A) Expression of TNF- $\alpha$ in chorio-decidua neutrophils was assessed by flow cytometry. rhIL-1ra significantly decreased the frequency of TNF- $\alpha^{+}$chorio-decidua neutrophils (Ctrl, $n=13 ;$ LPS, $n=$ 12; LPS + rhIL-1ra, $n=6$ ). (B-E) Chorioamnion-decidua sections from paraffin-embedded blocks were stained with DAPI (blue), IL-8/CXCL8 (red), and neutrophil elastase (green). Representative sections $(n=4)$ are shown from the animal groups: control (B), IA LPS (C), and LPS + rhIL-1ra (D). In magnified images in the inserts in $\mathbf{C}$ and $\mathbf{D}$ show cells with polymorphonuclear neutrophil morphology coexpressing IL-8/CXCL8 and neutrophil elastase. (E) Cell count/high-powered field (HPF, 40x) of IL-8/CXCL8+ neutrophils in the chorioamnion-decidua interface (Ctrl, $n=4 ;$ LPS, $n=4 ;$ LPS + rhIL-1ra, $n=4)$. ( $\mathbf{F}$ and $\mathbf{G}$ ) Expression of activation molecules in chorio-decidua neutrophils was assessed by flow cytometry (Ctrl, $n=7 ;$ LPS, $n=7 ;$ LPS + rhIL-1ra, $n=3$ ). rhIL-1ra decreased LPS-induced expression of CD16 nonsignificantly (F) and CD63 significantly (G) in chorio-decidua neutrophils. (H) Positive correlation of CD63 expression and TNF- $\alpha$ in neutrophils from LPS-exposed animals $\left(n=6 ; r^{2}=0.69 ; P=0.03\right)$. am, amnion; ch, chorion; dp, decidua parietalis. Data are mean $\pm \mathrm{SEM},{ }^{*} P<0.05$ between comparators by Mann-Whitney test. 
Table 1. mRNAS-seq analysis showing top 10 genes differentially expressed during chorioamnionitis.

\begin{tabular}{|c|c|c|c|c|c|}
\hline \multicolumn{3}{|c|}{ Rhesus } & \multicolumn{3}{|c|}{ Human } \\
\hline Gene symbol & Gene name & $\begin{array}{l}\text { LPS vs. ctrl } \\
\text { (fold } \uparrow)\end{array}$ & Gene symbol & Gene name & $\begin{array}{c}\text { Preterm chorio pos vs. } \\
\text { preterm chorio neg (fold } \uparrow \text { ) }\end{array}$ \\
\hline DEFB2L & $\beta$-Defensin 2 & 112 & PI3 & Peptidase inhibitor 3 & 201 \\
\hline CLEC4D & $\begin{array}{l}\text { C-Type Lectin Domain Family } \\
4 \text { Member D }\end{array}$ & 44 & $B C L 2 A 1$ & BCL2 Related Protein A1 & 73 \\
\hline S100A9 & $\begin{array}{c}\text { S100 Calcium Binding Protein } \\
\text { A9 }\end{array}$ & 39 & S100A8 & $\begin{array}{l}\text { S100 Calcium Binding } \\
\text { Protein A8 }\end{array}$ & 61 \\
\hline MYH15 & Myosin Heavy Chain 15 & 39 & S100A12 & $\begin{array}{l}\text { S100 Calcium Binding } \\
\text { Protein A12 }\end{array}$ & 60 \\
\hline LTB4R & Leukotriene B4 Receptor & 35 & ORM1 & Orosomucoid 1 & 44 \\
\hline$B C L 2 A 1$ & BCL2 Related Protein A1 & 29 & CHI3L1 & Chitinase 3 -like 1 & 29 \\
\hline
\end{tabular}

an inflammatory response (54), but IL-1 signaling is needed to transduce fetal/neonatal immune response to a variety of inflammatory stimuli in intrauterine or maternal systemic compartments $(31,46,47,55,56)$. Taken together with our data, IL-1 signaling appears to be a critical mediator in perinatal inflammation.

Inflammation at the maternal-fetal interface involves the fetal tissues (amnion and chorion) and maternal tissue (decidua). Leukocytes comprise about $70 \%$ of all chorio-decidua cells in the third trimester in both humans and rhesus (data not shown). Most of the leukocytes are macrophages, NK cells, or T cells. During chorioamnionitis, no changes in T cell, NK cells, invariant NKT (iNKT) cells, or Tregs were observed in the chorio-decidua. Interestingly, LPS exposure induced a small increase in monocyte/macrophage and B cells in the chorio-decidua, and Anakinra inhibited these increases (Supplemental Figure 5). Our results are consistent with a recent study reporting that B cells are activated and accumulate in higher numbers in the chorio-decidua during PTL in humans and inhibit LPS-induced neutrophil infiltration, intrauterine inflammation, and preterm birth in mice via IL-33 (an IL-1 family member) and progesterone-induced blocking factor axis (57). Although our study is focused on neutrophil biology at the maternal-fetal interface, IL-1 blockade can also inhibit macrophage-driven inflammation and macrophage-neutrophil interactions (58).

In contrast with our findings, studies in mouse models of preterm birth have demonstrated changes in frequency and proinflammatory and prolabor function for T cells, iNKT cells, and Tregs in the chorio-decidua, implicating these cells in the pathogenesis of inflammation-mediated preterm birth (59-62). Besides species differences, different route (systemic vs. IA route in our study) of administration of proinflammatory agents might explain these different findings. Indeed, systemic (i.p. or i.v.) administration of proinflammatory agents predominantly cause a maternal systemic inflammatory response, whereas inflammation in human preterm birth cases is largely in the intrauterine compartment (44).

Neutrophils infiltrating the chorio-decidua are of maternal origin (12), while neutrophils in the AF are largely of fetal origin (13), although a recent study reported mixed fetal/maternal origin of neutrophils in the AF (63). While rhIL-1ra reduced chorio-decidua neutrophil numbers by $\sim 90 \%$, the reduction in AF neutrophil count was not statistically significant, likely due to interanimal variability. It should be noted that the neutrophil counts were about 10-fold higher in the chorio-decidua compared with the AF. Thus, the overall effect of rhIL-1ra was to substantially reduce neutrophil numbers at the maternal-fetal interface. During IUI, the amnion can be potentially signaled by mediators in the AF or from the basal side by the chorio-decidua. Since microbial products can be identified in the AF in only $\sim 30 \%$ of human IUI cases, even with sensitive molecular detection methods (40), the compartmental location of inflammatory signals is not known in humans. The finding that IRAK1 is phosphorylated in both the rhesus model and human cases suggests that activation of 
A

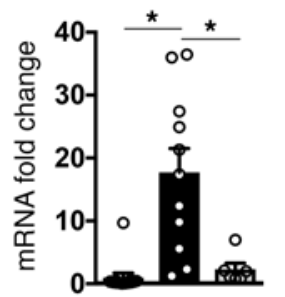

E

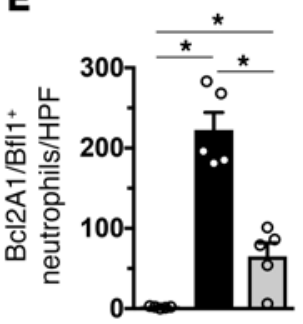

$\square$ ctrl $\square$ LPS $\square$ LPS+rhlL-1ra

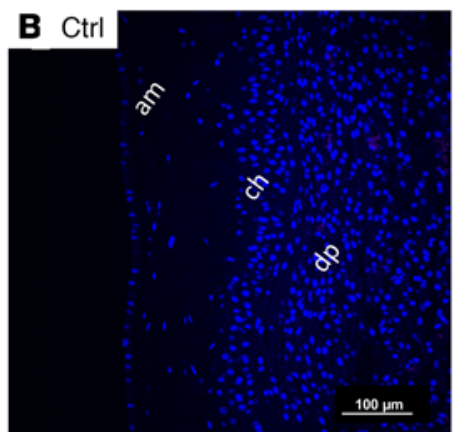

\section{$\mathbf{F}$} BCL2A1/BFL1 $B C L X L$ BCL2
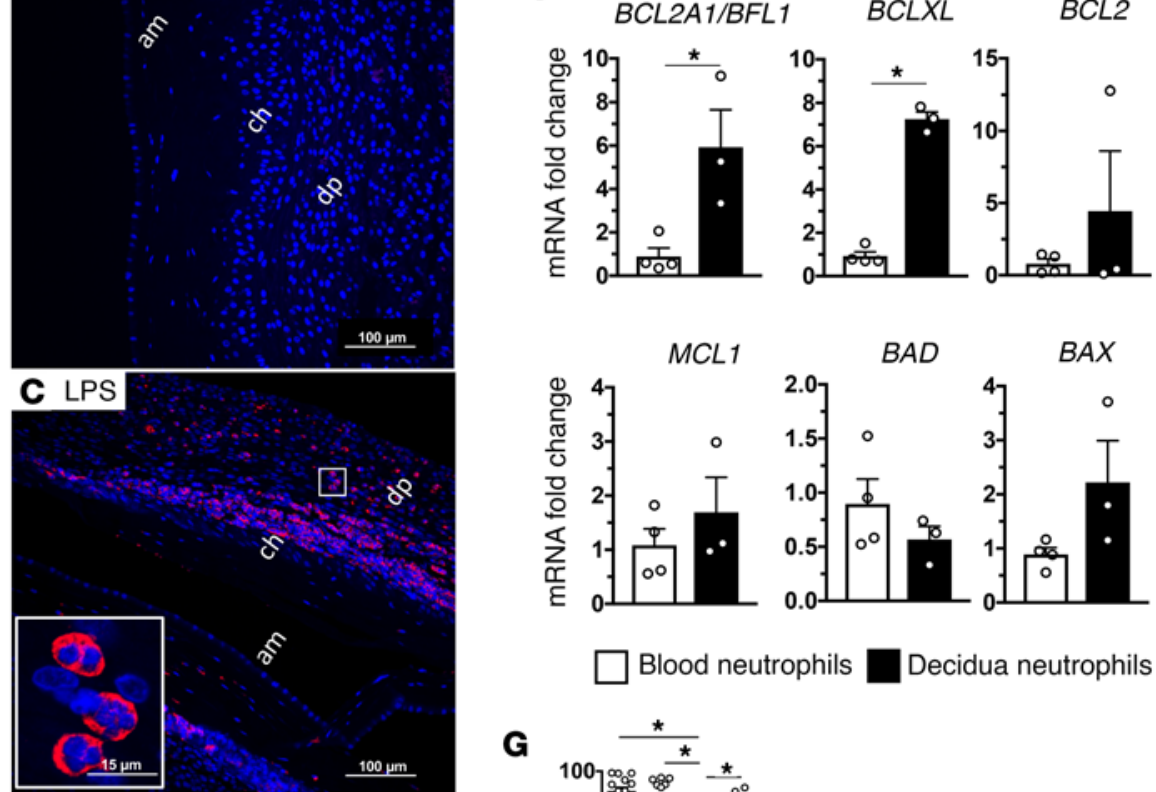

Blood neutrophils

Decidua neutrophils

\section{G}

D LPS+rhlL-1ra

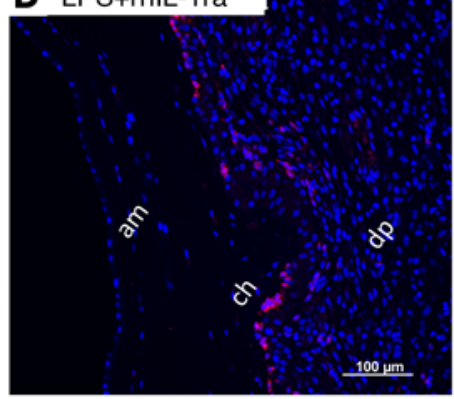

G

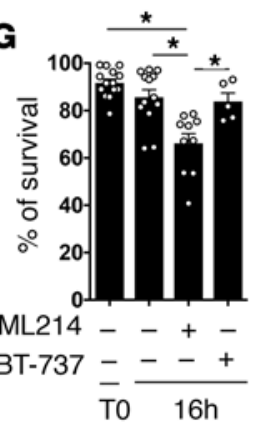

ML214 - + + -

ABT-737 $\frac{-}{\text { T0 }} \frac{-++}{16 \mathrm{~h}}$

Figure 5. IA LPS induced expression of the prosurvival factor BCL2A1/BFL1 in neutrophils is IL-1 dependent. Expression of BCL2A1/BFL1 mRNA by quantitative PCR in the rhesus CAD (A) (Ctrl, $n=13$; LPS, $n=11$; LPS + rhIL-1ra, $n=6$ ). Representative sections $(n=5)$ from rhesus chorioamnion-decidua paraffin-embedded blocks were stained with DAPI (blue) and BCL2A1/BFL1 (red). Controls (B), IA LPS (C), and LPS + IL-1ra (D). Magnified inset (60x) in C demonstrate cells with polymorphonuclear morphology expressing BCL2A1. (E) Cell count/high-powered field (HPF, 40x) of cells in the chorio-decidua interface showing fewer BCL2A1 ${ }^{+}$neutrophils in LPS + rhlL-1ra compared with LPS groups (Ctrl, $n=5$; LPS, $n=5$; LPS + rhIL-1ra, $n=5$ ). (F) Increased expression of BCL2A1/BFL1 and BCLXL in flow-sorted chorio-decidua neutrophils from IA LPS-exposed animals $(n=3)$ compared with immunomagnetic bead purified blood neutrophils from the same animal $(n=4)$. (C) Chorio-decidua cell suspension were cultured for 16 hours $(n=5-14)$. ML214 (inhibitor of BCL2A1) treatment ( $5 \mu \mathrm{M}$ ) decreased frequency of chorio-decidua annexin $\mathrm{V}^{-} / 7$ aad- (nonapoptotic) neutrophils by flow cytometry, while ABT-737 (inhibitor of BCL2 but not BCL2A1; $0.1 \mu \mathrm{M}$ ) did not show any significant effect. am, amnion; ch, chorion; dp, decidua parietalis. Data are mean $\pm \mathrm{SEM},{ }^{*} P<0.05$ between comparators by Mann-Whitney test. 


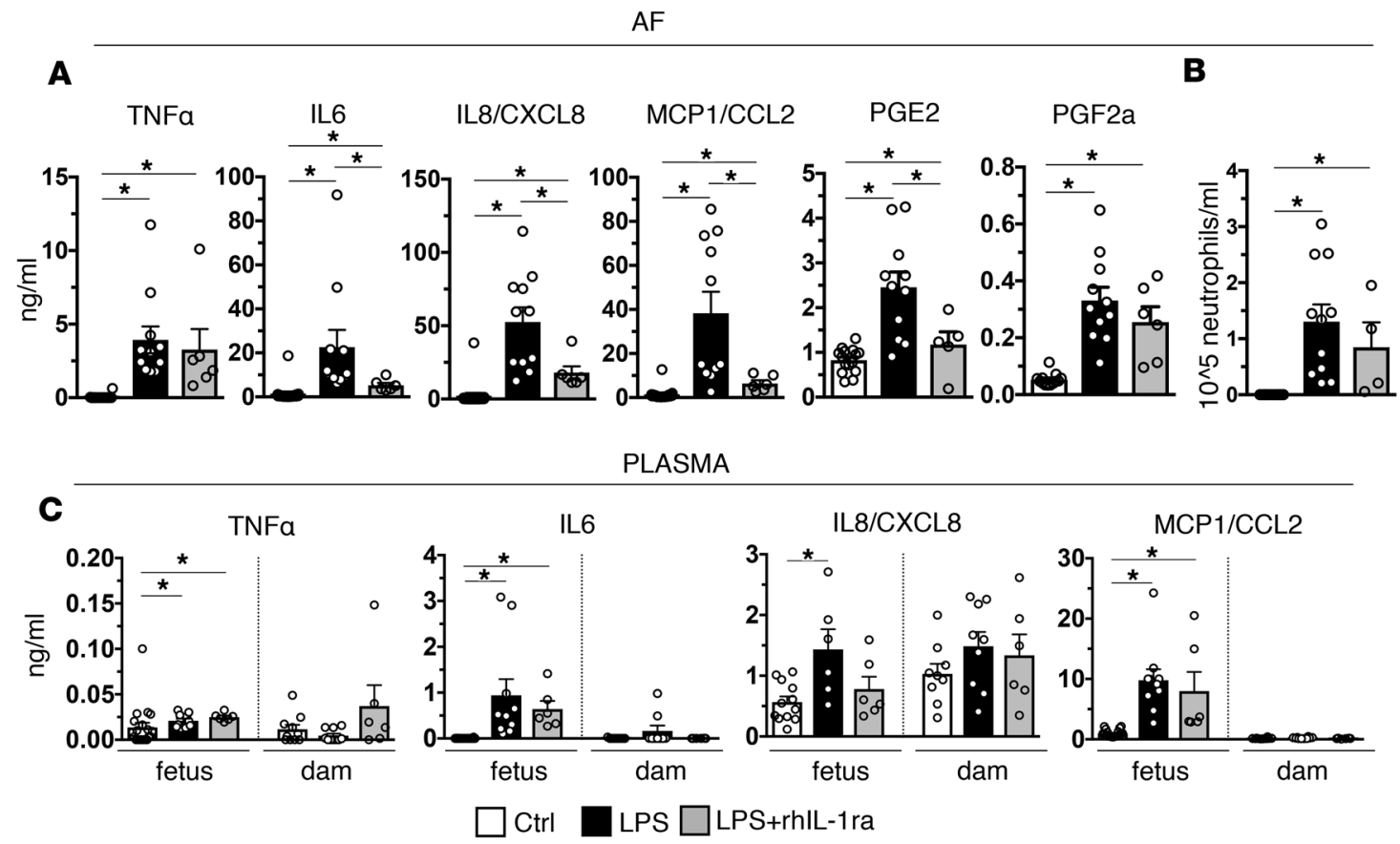

Figure 6. IL-1R blockade decreased inflammatory markers in amniotic fluid in IA LPS-exposed animals. Cytokine concentrations were measured by multiplex ELISA. Prostaglandin (PG) concentrations were measured in lipid extract of amniotic fluid by ELISA. (A) rhIL-1ra significantly decreased LPS-induced IL-6, IL-8/CXCL8, MCP1/CCL2, and PGE2, but not TNF- $\alpha$ or PGF2a levels (Ctrl, $n=16 ;$ LPS, $n=11$; LPS + rhIL-1ra, $n=6$ ). (B) There was a trend (nonsignificant) in reduced neutrophil counts in AF from rhIL-1ra + LPS- compared with LPS-exposed animals. AF neutrophil counts had high intragroup variability. (C) Compared with amniotic fluid, proinflammatory cytokine levels were lower in both fetal (Ctrl, $n=16$; LPS, $n=10$; LPS + rhIL-1ra, $n=6$ ) and maternal plasma (Ctrl, $n=10$; LPS, $n=10$; LPS + rhIL-1ra, $n=6$. Note that in dam plasma, these cytokines are low to undetectable, except for IL-8/CXCL8. Data are mean \pm $\mathrm{SEM},{ }^{*} P<0.05$ between comparators by Mann-Whitney test.

IRAK1 is a more general phenomenon in the cascade of IUI. The finding adds IUI to the list of inflammatory diseases/cancer in which IRAK1 is implicated in the pathogenesis or proposed as a target for therapy (64-66).

Neutrophils are classically known to be phagocytic cells that secrete proinflammatory mediators and cause tissue destruction (14). However, recent findings have shed light on the diversity within neutrophil populations. In tumors and the placenta, neutrophils can adopt regulatory roles, secrete antiinflammatory mediators like arginase-1 and indoleamine 2-3 deoxygenase, and subserve homeostatic functions (18, 67, 68 ). Whether regulatory neutrophil populations exist in the third-trimester placenta, and whether these populations can convert to the more proinflammatory phenotypes as a result of exposure to inflammatory mediators such as LPS resulting in PTL, is not known.

IL-1R blockade resulted in decreased LPS-induced TNF- $\alpha$, CXCL8, CD63, and CD16 expression in the neutrophils. CD63 is critical in processing and secretion of neutrophil elastase (69). CD16 expression is induced by TNF- $\alpha$ and mediates phagocytosis of immune complexes (70). CXCL8 production by neutrophils likely creates a feed-forward loop of more neutrophil recruitment and amplification of inflammation at the maternal-fetal interface. In contrast to our data of neutrophils being the predominant source of CXCL8, Gibbons et al. reported that neonatal, but not adult T cells, secrete CXCL8 constitutively and upon stimulation and potentially activate neutrophils (71). The discrepancies in the source of CXCL8 are likely explained by chorio-decidua T cells and neutrophils being predominantly maternal rather than fetal (12). Overall, our results demonstrate that IL-1 signaling mediates both neutrophil recruitment and a broad program of neutrophil activation at the maternal-fetal interface.

Neutrophils normally have a life span of a few hours in the circulation regulated by apoptosis (72). However, tissue neutrophils exposed to proinflammatory stimuli are known to have longer life spans (72). MCL1, an antiapoptotic factor of the BCL family, is a major mediator of neutrophil survival during inflammation (73). We report a previously unrecognized function for BCL2A1 in mediating enhanced survival of chorio-decidua neutrophils. We previously reported that MCL1 may function downstream of BCL2 and BCL2A1 in T cells (74). Thus, both BCL2A1 and MCL1 may be important mediators of neutrophil 


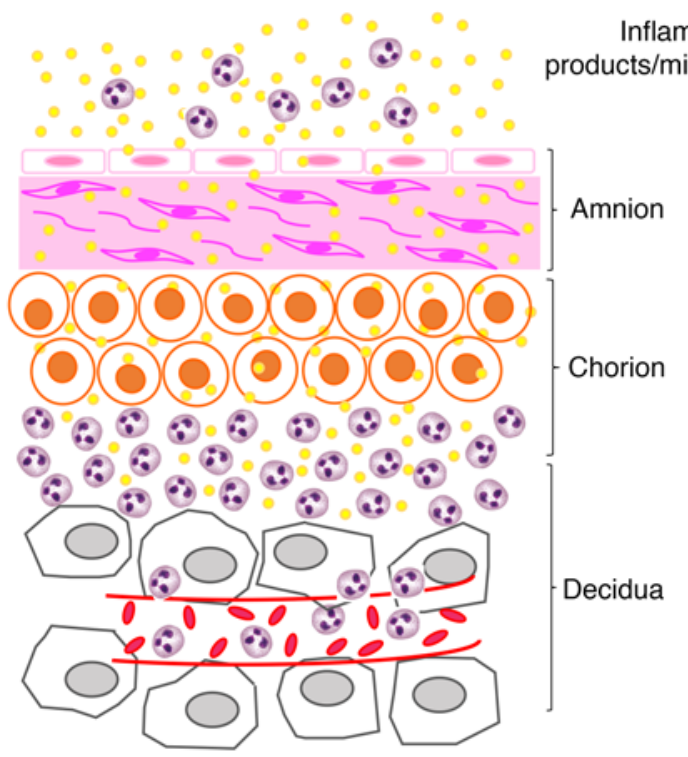

Inflammatory

anisms

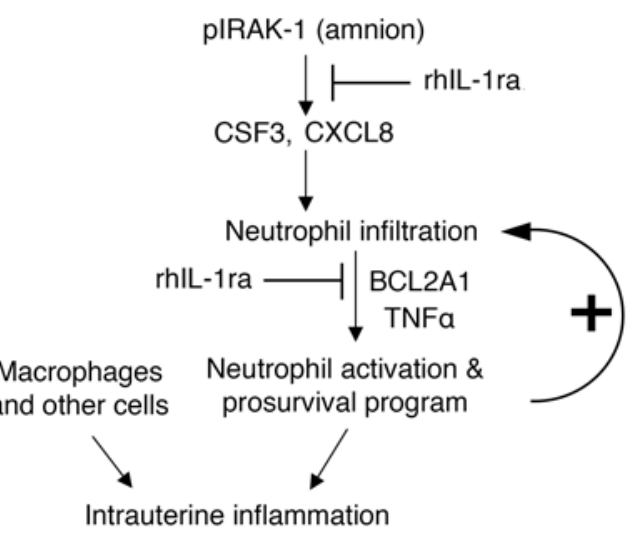

Figure 7. Schematic of IUI. Inflammatory mediators in the amniotic fluid and chorio-decidua activate the amnion, resulting in production of neutrophil chemoattractants in an IRAK1- and IL-1-dependent manner. Neutrophil accumulation occurs in the chorio-decidua interface. BCL2A1 increases neutrophil survival. Neutrophil activation mediated by IL-1 and TNF- $\alpha$ amplify the IUI. This conceptual model is based on previous reports and data from our study, and not all elements of the inflammation cascade have been formally verified in our study.

survival. A recent study reported the presence of natural cytotoxicity receptor expressing innate lymphoid cell-3 (NCR+ILC3) in the decidua and suggest that these NCR+ILC3 may play a role in enhancing neutrophil survival via secretion of CXCL8 and GM-CSF (75). Here, we show that IL-1 signaling is upstream of BCL2A1 induction, which may signal through the PI3K and JAK/STAT pathways $(37,73)$ during intrauterine inflammation. Dysregulated prosurvival of neutrophils is known to exacerbate chronic inflammation $(76,77)$, and therapeutic induction of apoptosis may be a novel antiinflammatory strategy (78). Our findings offer possibilities of new drug targets for intrauterine inflammation.

How might neutrophil-driven inflammation contribute to PTL? Neutrophil-derived proteinases can weaken the collagen scaffolding of the amnion, leading to rupture of membranes and PTL (79-81). PG, proinflammatory cytokines, and contractile associated proteins - particularly connexin- 43 and oxytocin receptor can directly stimulate uterine contractions $(21,82,83)$. Chorio-decidua neutrophils may reciprocally activate $\mathrm{B}$ cells, CD8 T cells, macrophages, and other cells in positively reinforcing intrauterine inflammation $(57,84)$. However, intrauterine inflammation does not invariably lead to PTL. Higher compared with lower levels of IL-6 and the alarmin HMGB1 in AFs of women with PTL more frequently resulted in preterm birth $(40,85)$. Priming by the interferon-1 signaling significantly decreased the LPS dose threshold trigerring preterm birth in mice (86). These results suggest that there may be quantitative and/or qualitative aspects of intrauterine inflammation that may variably result in PTL/preterm birth. Our data are at some variance with results in pregnant mice in which complete neutrophil depletion did not reduce placental inflammation or prevent PTL $(15,16)$. Prior studies demonstrated that neutrophil depletion in mice led to substantial elevations in myeloid hematopoietic progenitors, the myelopoietic/proinflammatory cytokines G-CSF, IL-17, and IL-23 (87), potentially limiting the usefulness of the neutrophil-depletion approach. Furthermore, there are substantial differences in reproductive biology between mice and humans. Our study cannot definitively establish if neutrophils are required to mediate IUI, since IL-1 signaling may independently mediate neutrophil activity and inflammation at the maternal-fetal interface.

AF levels of IL-6 and PG are validated biomarkers of inflammation-mediated PTL $(21,40,88)$. IL-1 blockade effectively decreased LPS-induced increases in both AF IL- 6 and PGE2. In addition, IL-1 blockade decreased AF levels of IL-1 $\beta$ and other proinflammatory agonists, but not TNF- $\alpha$. The reason for the rhIL-1ra-mediated decrease in choriodecidua neutrophil-derived TNF- $\alpha$ but not AF TNF- $\alpha$ is not clear. Although the maternal-fetal membranes comprising the amnion, chorion, and decidua are a major source of inflammatory mediators during intrauterine inflammation, other sources including fetal-derived neutro- 
phils and fetal lung may also contribute to AF cytokines. Consistent with decreases in AF mediators, IL-1 blockade also decreased expression of several inflammatory mediators in the maternal-fetal membranes. Thus, the IL-1 blockade decreased inflammatory mediators associated with PTL in the AF and the maternal-fetal membranes, demonstrating a broad multicompartment antiinflammatory effect.

Antibiotic therapy for infection-induced PTL has been disappointing so far, likely because of the residual intrauterine inflammation (89). Together with previous literature, our results suggest a model for the pathogenesis of intrauterine inflammation (Figure 7), proposing a key role for IL-1 signaling to mediate the initiation, amplification of inflammation, and regulation of survival and activity of neutrophils at the maternal-fetal interface. Although Anakinra use during pregnancy has been reported to be without major side effects in a small number of women (90), conclusive safety during pregnancy needs to be established.

\section{Methods}

Animals. Normally cycling, adult female rhesus macaques (Macaca mulatta) $(n=43)$ were time mated. At $\sim 130$ days of gestation ( $\sim 80 \%$ of term gestation), the pregnant rhesus received either $1 \mathrm{ml}$ saline solution $(n$ $=16$ ) or $1 \mathrm{mg}$ LPS (MilliporeSigma) in $1 \mathrm{ml}$ saline solution by ultrasound-guided IA injection. Dams were surgically delivered 16 hours $(n=13)$ or 48 hours $(n=8)$ later. Multiparous macaques and their fetuses were similar in demographics (Supplemental Table 1). After delivery, fetuses were euthanized with pentobarbital, and fetal tissues were collected. There were no spontaneous deaths or PTL in the animals. IL-1 signaling was blocked by rhIL-1RA (Anakinra, Sobi) given to the pregnant monkey IA (50 mg) and s.c. (100 mg) 1 and 3 hours before LPS, as previously described (31) (Supplemental Figure 4A).

Human samples. Thirty pregnant women at pregnancies from $26^{0}$ to $36^{6}$ weeks were recruited. Cohorts were developed based on a detailed histopathologic diagnosis of chorioamnionitis based on Redline's criteria (91). Maternal and neonatal demographic characteristics of the cohorts are shown in Supplemental Table 2.

Chorion, amnion, decidua tissue preparation. Both rhesus and human purified decidua cell suspensions were prepared as previously described (18). Briefly, extraplacental membranes were dissected away from the placenta. Chorio-decidua cells were scraped from the amnion. Amnion was then separated from fetal membranes and flash-frozen for protein and RNA studies. Decidua tissue was washed and digested with Dispase II (Invitrogen) plus collagenase A (Roche Diagnostics) for 30 minutes, followed by DNase I (Roche Diagnostics) treatment for another 30 minutes. Cell suspensions were filtered and the RBCs were lysed and prepared for flow cytometry. Viability was $>90 \%$ by trypan blue exclusion test.

Flow cytometry. mAbs used for multiparameter flow cytometry (LSR Fortessa 2, BD Biosciences) are listed in the Supplemental Table 3. Immunophenotyping was done as described (18) on fresh chorio-decidua cell suspensions - except for $\mathrm{T}$ cell phenotyping, which was done on cultured cells since cell isolation procedure downregulates CD4/8 expression (18). Chorio-decidua cell TNF- $\alpha$ expression was measured by flow cytometry with anti-TNF- $\alpha \mathrm{Ab}$ (Cytofix/Cytoperm; BD Bioscience). To measure cytokine expression induced by in vivo exposures, flow cytometry was done on cells immediately after isolation without any stimulation and/or intracellular blockers. For all protocols, cells were treated with $20 \mu \mathrm{g} / \mathrm{ml}$ human IgG to block Fc receptors, stained for surface markers for 30 minutes at $4^{\circ} \mathrm{C}$ in PBS, washed, and fixed in fixative stabilizing buffer (BD Bioscience). All antibodies were titrated for optimal detection of positive populations and mean fluorescence intensity. At least 500,000 events were recorded for each sample. Doublets were excluded based on forward scatter properties, and dead cells were excluded using LIVE/DEAD Fixable Aqua dead cell stain (Invitrogen). Unstained and negative biological population were used to determine positive staining for each marker.

Data were analyzed using FlowJo version 9.5.2 software (TreeStar Inc.). Supplemental Figure 1 shows the flow cytometry gating strategy used to characterize the different chorio-decidua subpopulations.

Neutrophil isolation and RNA extraction. Peripheral blood neutrophils were isolated from both rhesus dams and female young healthy donors (median age 32 years; range 28-42 years) using human MACSxpress neutrophil isolation kit (Miltenyi Biotec), according to the manufacturer's instructions. Neutrophil purity was $>97 \%$, as assessed by flow cytometry (Supplemental Figure 9A). Rhesus chorio-decidua neutrophils and CD45- cells were purified by FACSAria Cell Sorter (BD Bioscience) using the same gating strategy as immunophenotyping studies. Neutrophil as well as CD45- cell purity was $>98 \%$ (data not shown). Human chorio-decidua neutrophils were purified by positive selection using anti-CD66b MicroBeads (Miltenyi Biotec, Supplemental Figure 9B). Total RNA was extracted from the purified neutrophils (2 $\times 10^{6}$ to $4 \times 10^{6}$ ) by adding TRIzol (Thermo Fisher Scientific) and subsequently using Direct-Zol RNA MicroPrep kit (ZYMO Research) to efficiently extract small quantities of RNA. 
Apoptosis experiments. Neutrophils were cultured overnight (16 hours) at $37^{\circ} \mathrm{C}$, in $5 \% \mathrm{CO}_{2}$ in $\mathrm{DMEM}$ / F12 containing 10\% FBS, $100 \mathrm{IU} / \mathrm{ml}$ penicillin, $100 \mathrm{IU} / \mathrm{ml}$ streptomycin, and $2 \mathrm{mmol} / 1$ glutamine in 24 -well plate $\left(1 \times 10^{6}\right.$ cells $\left./ \mathrm{ml}\right)$. Chorio-decidua cells were stained with a cocktail of Abs as above for immunophenotyping and analyzed by flow cytometry within 30 minutes, and cell survival was indicated as percentage of annexin $\mathrm{V}^{-} / 7 \mathrm{aad}^{-}$cells (BD Bioscience).

Different concentrations of BCL2A1 inhibitor (ML214, NIH molecular libraries program) (38) or of BCL2 inhibitor that does not inhibit BCL2A1 (ABT-737) were used in the survival inhibition experiments. The chosen doses were optimum based on dose response curves that were generated using blood neutrophils. ABT737 concentrations $\geq 1 \mu \mathrm{M}$ were toxic to the cells (data not shown).

CXCL8, BCL2A1, and neutrophil elastase immunohistology. Immunofluorescence was performed as previously described (18). Briefly, paraffin-embedded rhesus fetal membrane sections were sectioned and subjected to antigen retrieval by microwave boiling in citrate buffer, followed by incubation with either anti-human CXCL8 (G265-8; 1:25 dilution; BD Biosciences), BCL2A1 (b450; 1:50 dilution; LSBio), or neutrophil elastase (ab68762; $1: 100$ dilution, Abcam) in 10\% normal horse serum $/ 0.2 \%$ Tween-20 at $4^{\circ} \mathrm{C}$ overnight. Staining was visualized using fluorescently labeled secondary antibodies (AF594; 1:200 dilution; Invitrogen) for 1 hour at room temperature. Nuclear counterstain was achieved using Vector Shield HardSet mounting medium with DAPI (Vector Laboratories).

Stained slides were imaged on confocal microscopy for colocalization at $20 \times, 40 \times$, or $60 \times$ magnification with 1,024 × 1,024 pixel resolution on a Nikon Eclipse A1RSi inverted microscope (Nikon Instruments Inc.). Images were collected using a Zeiss Axioplan 2 microscope and AxioVision 4 software (Zeiss).

Histologic evaluation of fetal membranes for chorioamnionitis. H\&E staining was performed for rhesus and human fetal membrane sections, and staining was photographed. H\&E-stained sections of human fetal membranes were scored in a blinded manner (by S.G. Kallapur) for chorioamnionitis using criteria outlined by Redline et al. based on numbers and depth of neutrophil infiltration of the tissue (91).

Cytokines, PG, and Anakinra ELISA. Cytokine/chemokine concentrations in AF, fetal, and maternal plasma were determined by Luminex using nonhuman primate multiplex kits (MilliporeSigma). Lipids were extracted from the AF using methanol to measure PG PGE2 (Oxford Biomedical Research) and PGF2a (Cayman Chemical) concentrations. Anakinra levels in AF, fetal, and maternal plasma were determined by human IL-1ra/ IL-1F3 Quantikine ELISA kit (R\&D System). This kit has low cross-reactivity to rhesus IL-1ra.

Quantitative PCR and $m R N A$-seq analyses. Total RNA was extracted from neutrophils, snap-frozen chorio-decidua, and amnion after homogenizing in TRIzol (Invitrogen). RNA concentration and quality were measured by Nanodrop spectrophotometer (Thermo Fisher Scientific). Reverse transcription of the RNA was performed using Verso cDNA synthesis kit (Thermo Fisher Scientific), following the manufacturer's protocol. Quantitative PCR (qPCR) was carried out in a StepOnePlus real-time PCR system (Invitrogen) following standard cycling conditions. qPCR assays were performed with rhesus- and human-specific TaqMan gene expression primers (Invitrogen, Supplemental Table 4). Eukaryotic 18S rRNA (Invitrogen) was an endogenous control for normalization of the target RNAs, and a sample from an IA saline-injected rhesus animal and a human chorio-negative sample was used as the calibrator. The values were expressed relative to the average value of the control group. For mRNA sequencing (mRNA-seq) analyses samples with RNA integrity number $(\mathrm{RIN}) \geq 8.0$ were used for mRNA-seq. RNA-library preparation was performed at the DNA core facility (Cincinnati Children's Hospital Medical Center). We used single-end read sequencing by Illumina HiSeq2500 Ultra-High-throughput sequencing system (Illumina Inc.) at an average depth of 50 million reads per sample. Raw sequences were accepted once they passed the quality filtering parameters used in the Illumina GA Pipeline. Sequenced reads were mapped to the reference rhesus genome assembly MMUL1.0.

Western Blot for pIRAK1 in the amnion. Both rhesus and human amnion were peeled off from the chorio-decidua layer. Tissue extracts were resolved through SDS-PAGE using 4\%-12\% separating gel (Invitrogen). Proteins were transferred to Hybond enhanced chemiluminescence (ECL) nitrocellulose membrane (Amersham Pharmacia Biotech) using a semi-dry transfer system (Bio-Rad) and blocked with 5\% dried milk in PBS and 0.1\% Tween-20 (MilliporeSigma). Blots were probed with anti-phospho IRAK1 antibody (BIOSS, bs-319R) or $\beta$-actin antibody (MilliporeSigma, A5060) overnight at $4^{\circ} \mathrm{C}$. Binding of HRP-labeled goat anti-rabbit antibody (sc-2004, Santa Cruz Biotechnology Inc.) was determined using SuperSignalWest Chemiluminescent Substrate (Thermo Fisher Scientific). Blots were stripped with Restore Western Blot Stripping Buffer (Thermo Fisher Scientific), as required. The blots were imaged and quantified using ImageJ software (NIH), and the results were reported as $\mathrm{pIRAK} 1 / \beta$-actin ratio. 
Statistics. Prism version 5.0b software (GraphPad) was used to analyze data. Values were expressed as means \pm SEM. Two-tailed Mann-Whitney $U$ tests (for nonnormally distributed continuous variables and 2-tailed Student $t$ test for Gaussian distributed data points) and Fisher's exact test for categorical variables were used to determine differences between groups. Results were considered significant for $P \leq 0.05$.

Study approval. All animal procedures were approved by the IACUC at the UCD. Pregnant women provided a written informed consent from 2014-2017 under a protocol approved by the IRBs of Cincinnati Children's Hospital and University of Cincinnati (no. 2013-2243).

\section{Author contributions}

PP, PS, SB, CWP, CJ, FK, CMR, ED, LAM, DAH, NS, CAC, AHJ, and SGK participated in data generation. PP, PS, NS, AHJ, CAC, and SGK participated in analysis and interpretation of data. ED and DAH provided materials and technical support and participated in critical review of the manuscript. AHJ, CAC, and SGK participated in the conception and design of the study and obtained the funding. PP and SGK wrote the manuscript. All authors have reviewed the manuscript and approve the final version.

\section{Acknowledgments}

This study was supported Burroughs Wellcome grant (CAC), MOD innovation catalyst award (SGK), HD90856 (SGK and DAH), and Cincinnati Children's Hospital's Academic Research Council grant for perinatal infection and inflammation collaborative (CAC).

Address correspondence to: Suhas G. Kallapur, David Geffen School of Medicine at UCLA, Mattel Children's Hospital UCLA, 10833 Le Conte Avenue, Room B2-375 MDCC, Los Angeles, California 90095, USA. Phone: 310.206.8489; Email: skallapur@mednet.ucla.edu.

SGK and PP's present address is: Department of Pediatrics, David Geffen School of Medicine at UCLA.

CWP's present address is: Department of Obstetrics and Gynecology, Seoul National University College of Medicine, Seoul, South Korea.

1. Dunn PM. Sir George Newman, MD (1870-1948) and the prevention of perinatal disease. Arch Dis Child Fetal Neonatal Ed. 2005;90(3):F278-F280.

2. Martin JA, Hamilton BE, Osterman MJ, Driscoll AK, Mathews TJ. Births: Final Data for 2015. Natl Vital Stat Rep. 2017;66(1):1.

3. Gravett MG, Rubens CE, Global Alliance to Prevent Prematurity Stillbirth Technical Team. A framework for strategic investments in research to reduce the global burden of preterm birth. Am J Obstet Gynecol. 2012;207(5):368-373.

4. Liu L, et al. Global, regional, and national causes of child mortality: an updated systematic analysis for 2010 with time trends since 2000. Lancet. 2012;379(9832):2151-2161.

5. Goldenberg RL, Culhane JF, Iams JD, Romero R. Epidemiology and causes of preterm birth. Lancet. 2008;371(9606):75-84.

6. DiGiulio DB, et al. Microbial prevalence, diversity and abundance in amniotic fluid during preterm labor: a molecular and culture-based investigation. PLoS One. 2008;3(8):e3056.

7. Pappas A, et al. Chorioamnionitis and early childhood outcomes among extremely low-gestational-age neonates. JAMA Pediatr. 2014;168(2):137-147.

8. Been JV, Lievense S, Zimmermann LJ, Kramer BW, Wolfs TG. Chorioamnionitis as a risk factor for necrotizing enterocolitis: a systematic review and meta-analysis. J Pediatr. 2013;162(2):236-42.e2.

9. Speer CP. Inflammation and bronchopulmonary dysplasia: a continuing story. Semin Fetal Neonatal Med. 2006;11(5):354-362.

10. Redline RW. Inflammatory response in acute chorioamnionitis. Semin Fetal Neonatal Med. 2012;17(1):20-25.

11. Romero R, Dey SK, Fisher SJ. Preterm labor: one syndrome, many causes. Science. 2014;345(6198):760-765.

12. Steel JH, O'donoghue K, Kennea NL, Sullivan MH, Edwards AD. Maternal origin of inflammatory leukocytes in preterm fetal membranes, shown by fluorescence in situ hybridisation. Placenta. 2005;26(8-9):672-677.

13. Sampson JE, et al. Fetal origin of amniotic fluid polymorphonuclear leukocytes. Am J Obstet Gynecol. 1997;176(1 Pt 1):77-81.

14. Mantovani A, Cassatella MA, Costantini C, Jaillon S. Neutrophils in the activation and regulation of innate and adaptive immunity. Nat Rev Immunol. 2011;11(8):519-531.

15. Rinaldi SF, Catalano RD, Wade J, Rossi AG, Norman JE. Decidual neutrophil infiltration is not required for preterm birth in a mouse model of infection-induced preterm labor. J Immunol. 2014;192(5):2315-2325.

16. Filipovich Y, et al. Depletion of polymorphonuclear leukocytes has no effect on preterm delivery in a mouse model of Escherichia coli-induced labor. Am J Obstet Gynecol. 2015;213(5):697.e1-697.10.

17. Hamilton SA, Tower CL, Jones RL. Identification of chemokines associated with the recruitment of decidual leukocytes in human labour: potential novel targets for preterm labour. PLoS One. 2013;8(2):e56946.

18. Presicce $P$, et al. Neutrophil recruitment and activation in decidua with intra-amniotic IL-1beta in the preterm rhesus macaque Biol Reprod. 2015;92(2):56. 
19. Gomez-Lopez N, StLouis D, Lehr MA, Sanchez-Rodriguez EN, Arenas-Hernandez M. Immune cells in term and preterm labor. Cell Mol Immunol. 2014;11(6):571-581.

20. Sadowsky DW, Adams KM, Gravett MG, Witkin SS, Novy MJ. Preterm labor is induced by intraamniotic infusions of interleukin-1beta and tumor necrosis factor-alpha but not by interleukin-6 or interleukin-8 in a nonhuman primate model. Am J Obstet Gynecol. 2006;195(6):1578-1589.

21. Sadowsky DW, Haluska GJ, Gravett MG, Witkin SS, Novy MJ. Indomethacin blocks interleukin 1beta-induced myometrial contractions in pregnant rhesus monkeys. Am J Obstet Gynecol. 2000;183(1):173-180.

22. Sadowsky DW, Novy MJ, Witkin SS, Gravett MG. Dexamethasone or interleukin-10 blocks interleukin-1beta-induced uterine contractions in pregnant rhesus monkeys. Am J Obstet Gynecol. 2003;188(1):252-263.

23. Romero R, Mazor M, Tartakovsky B. Systemic administration of interleukin-1 induces preterm parturition in mice. Am J Obstet Gynecol. 1991;165(4 Pt 1):969-971.

24. Hirsch E, Filipovich Y, Mahendroo M. Signaling via the type I IL-1 and TNF receptors is necessary for bacterially induced preterm labor in a murine model. Am J Obstet Gynecol. 2006;194(5):1334-1340.

25. Kim J, et al. Transcriptome landscape of the human placenta. BMC Genomics. 2012;13:115.

26. Dolan SM, et al. Synopsis of preterm birth genetic association studies: the preterm birth genetics knowledge base (PTBGene). Public Health Genomics. 2010;13(7-8):514-523.

27. Uzun A, et al. dbPTB: a database for preterm birth. Database (Oxford). 2012;2012:bar069.

28. Guzeloglu-Kayisli O, et al. Mechanisms of chorioamnionitis-associated preterm birth: interleukin- $1 \beta$ inhibits progesterone receptor expression in decidual cells. J Pathol. 2015;237(4):423-434.

29. Gravett MG, Haluska GJ, Cook MJ, Novy MJ. Fetal and maternal endocrine responses to experimental intrauterine infection in rhesus monkeys. Am J Obstet Gynecol. 1996;174(6):1725-31; discussion 1731

30. Golos TG, Bondarenko GI, Dambaeva SV, Breburda EE, Durning M. On the role of placental Major Histocompatibility Complex and decidual leukocytes in implantation and pregnancy success using non-human primate models. Int J Dev Biol. 2010;54(2-3):431-443

31. Rueda CM, et al. Lipopolysaccharide-Induced Chorioamnionitis Promotes IL-1-Dependent Inflammatory FOXP3+ CD4+ T Cells in the Fetal Rhesus Macaque. J Immunol. 2016;196(9):3706-3715.

32. Dinarello CA. Blocking IL-1 in systemic inflammation. J Exp Med. 2005;201(9):1355-1359.

33. Rider P, et al. IL-1 $\alpha$ and IL-1 $\beta$ recruit different myeloid cells and promote different stages of sterile inflammation. J Immunol. 2011;187(9):4835-4843.

34. Kineret [package insert]. Stockholm, Sweden: Sobi; 2013.

35. Goldbach-Mansky R, et al. Neonatal-onset multisystem inflammatory disease responsive to interleukin-1beta inhibition. $N$ Engl JMed. 2006;355(6):581-592.

36. Gottipati S, Rao NL, Fung-Leung WP. IRAK1: a critical signaling mediator of innate immunity. Cell Signal. 2008;20(2):269-276.

37. Berberich I, Hildeman DA. The Bcl2a1 gene cluster finally knocked out: first clues to understanding the enigmatic role of the Bcl-2 protein A1. Cell Death Differ. 2017;24(4):572-574.

38. Bittker JA, et al. Probe Reports from the NIH Molecular Libraries Program. Bethesda, MD: NIH; 2010. https://www.ncbi.nlm. nih.gov/books/NBK47352/. Accessed February 22, 2018.

39. Vogler M, et al. Concurrent up-regulation of BCL-XL and BCL2A1 induces approximately 1000-fold resistance to ABT-737 in chronic lymphocytic leukemia. Blood. 2009;113(18):4403-4413.

40. Romero R, et al. Prevalence and clinical significance of sterile intra-amniotic inflammation in patients with preterm labor and intact membranes. Am J Reprod Immunol. 2014;72(5):458-474.

41. Romero R, et al. Evidence of perturbations of the cytokine network in preterm labor. Am J Obstet Gynecol. 2015;213(6):836. e1-836.e18.

42. KNOX IC, HOERNER JK. The role of infection in premature rupture of the membranes. Am J Obstet Gynecol. 1950;59(1):190-4, illust.

43. Romero R, et al. Proteomic analysis of amniotic fluid to identify women with preterm labor and intra-amniotic inflammation/infection: the use of a novel computational method to analyze mass spectrometric profiling. J Matern Fetal Neonatal Med. 2008;21(6):367-388.

44. Dulay AT, et al. Compartmentalization of acute phase reactants Interleukin-6, C-Reactive Protein and Procalcitonin as biomarkers of intra-amniotic infection and chorioamnionitis. Cytokine. 2015;76(2):236-243.

45. Bukowski R, et al. Onset of human preterm and term birth is related to unique inflammatory transcriptome profiles at the maternal fetal interface. PeerJ. 2017;5:e3685.

46. Girard S, Tremblay L, Lepage M, Sébire G. IL-1 receptor antagonist protects against placental and neurodevelopmental defects induced by maternal inflammation. J Immunol. 2010;184(7):3997-4005.

47. Nadeau-Vallée M, et al. Novel Noncompetitive IL-1 Receptor-Biased Ligand Prevents Infection- and Inflammation-Induced Preterm Birth. J Immunol. 2015;195(7):3402-3415.

48. Fidel PL, et al. Treatment with the interleukin-I receptor antagonist and soluble tumor necrosis factor receptor Fc fusion protein does not prevent endotoxin-induced preterm parturition in mice. J Soc Gynecol Investig. 1997;4(1):22-26.

49. Baggia S, Gravett MG, Witkin SS, Haluska GJ, Novy MJ. Interleukin-1 beta intra-amniotic infusion induces tumor necrosis factor-alpha, prostaglandin production, and preterm contractions in pregnant rhesus monkeys. J Soc Gynecol Investig. 1996;3(3):121-126.

50. Adams Waldorf KM, Persing D, Novy MJ, Sadowsky DW, Gravett MG. Pretreatment with toll-like receptor 4 antagonist inhibits lipopolysaccharide-induced preterm uterine contractility, cytokines, and prostaglandins in rhesus monkeys. Reprod Sci. 2008;15(2):121-127.

51. Kallapur SG, et al. Intra-amniotic IL-1 $\beta$ induces fetal inflammation in rhesus monkeys and alters the regulatory T cell/IL-17 balance. J Immunol. 2013;191(3):1102-1109.

52. Adams Waldorf KM, et al. Choriodecidual group B streptococcal inoculation induces fetal lung injury without intra-amniotic infection and preterm labor in Macaca nemestrina. PLoS One. 2011;6(12):e28972. 
53. Boldenow E, et al. Group B Streptococcus circumvents neutrophils and neutrophil extracellular traps during amniotic cavity invasion and preterm labor. Sci Immunol. 2016;1(4):eaah4576.

54. Leon LR, Conn CA, Glaccum M, Kluger MJ. IL-1 type I receptor mediates acute phase response to turpentine, but not lipopolysaccharide, in mice. Am J Physiol. 1996;271(6 Pt 2):R1668-R1675.

55. Liao J, et al. The NLRP3 inflammasome is critically involved in the development of bronchopulmonary dysplasia. Nat Commun. $2015 ; 6: 8977$.

56. Kallapur SG, et al. IL-1 mediates pulmonary and systemic inflammatory responses to chorioamnionitis induced by lipopolysaccharide. Am J Respir Crit Care Med. 2009;179(10):955-961.

57. Huang B, et al. Interleukin-33-induced expression of PIBF1 by decidual B cells protects against preterm labor. Nat Med. 2017;23(1):128-135

58. Mosser DM, Edwards JP. Exploring the full spectrum of macrophage activation. Nat Rev Immunol. 2008;8(12):958-969.

59. Arenas-Hernandez M, Romero R, St Louis D, Hassan SS, Kaye EB, Gomez-Lopez N. An imbalance between innate and adaptive immune cells at the maternal-fetal interface occurs prior to endotoxin-induced preterm birth. Cell Mol Immunol. 2016;13(4):462-473

60. Gomez-Lopez N, et al. In vivo T-cell activation by a monoclonal $\alpha \mathrm{CD} 3 \varepsilon$ antibody induces preterm labor and birth. Am $J$ Reprod Immunol. 2016;76(5):386-390.

61. Gomez-Lopez N, et al. In vivo activation of invariant natural killer T cells induces systemic and local alterations in T-cell subsets prior to preterm birth. Clin Exp Immunol. 2017;189(2):211-225.

62. St Louis D, et al. Invariant NKT Cell Activation Induces Late Preterm Birth That Is Attenuated by Rosiglitazone. J Immunol. 2016;196(3):1044-1059.

63. Gomez-Lopez N, et al. Are amniotic fluid neutrophils in women with intraamniotic infection and/or inflammation of fetal or maternal origin? Am J Obstet Gynecol. 2017;217(6):693.e1-693.e16.

64. Chandra R, et al. IRAK1-dependent signaling mediates mortality in polymicrobial sepsis. Inflammation. 2013;36(6):1503-1512.

65. Jacob CO, et al. Identification of IRAK1 as a risk gene with critical role in the pathogenesis of systemic lupus erythematosus. Proc Natl Acad Sci USA. 2009;106(15):6256-6261.

66. Jain A, Kaczanowska S, Davila E. IL-1 Receptor-Associated Kinase Signaling and Its Role in Inflammation, Cancer Progression, and Therapy Resistance. Front Immunol. 2014;5:553.

67. Nicolás-Ávila JÁ, Adrover JM, Hidalgo A. Neutrophils in Homeostasis, Immunity, and Cancer. Immunity. 2017;46(1):15-28.

68. Amsalem $\mathrm{H}$, et al. Identification of a novel neutrophil population: proangiogenic granulocytes in second-trimester human decidua. J Immunol. 2014;193(6):3070-3079.

69. Källquist L, et al. The tetraspanin CD63 is involved in granule targeting of neutrophil elastase. Blood. 2008;112(8):3444-3454.

70. Fossati G, Moots RJ, Bucknall RC, Edwards SW. Differential role of neutrophil Fcgamma receptor IIIB (CD16) in phagocytosis, bacterial killing, and responses to immune complexes. Arthritis Rheum. 2002;46(5):1351-1361.

71. Gibbons D, et al. Interleukin-8 (CXCL8) production is a signatory T cell effector function of human newborn infants. Nat Med. 2014;20(10):1206-1210.

72. Luo HR, Loison F. Constitutive neutrophil apoptosis: mechanisms and regulation. Am J Hematol. 2008;83(4):288-295.

73. Vier J, Groth M, Sochalska M, Kirschnek S. The anti-apoptotic Bcl-2 family protein A1/Bfl-1 regulates neutrophil survival and homeostasis and is controlled via PI3K and JAK/STAT signaling. Cell Death Dis. 2016;7:e2103.

74. Tripathi P, Koss B, Opferman JT, Hildeman DA. Mcl-1 antagonizes Bax/Bak to promote effector CD4(+) and CD8(+) T-cell responses. Cell Death Differ. 2013;20(8):998-1007.

75. Croxatto D, et al. Group 3 innate lymphoid cells regulate neutrophil migration and function in human decidua. Mucosal Immunol. 2016;9(6):1372-1383.

76. Rossi AG, et al. Cyclin-dependent kinase inhibitors enhance the resolution of inflammation by promoting inflammatory cell apoptosis. Nat Med. 2006;12(9):1056-1064

77. Koedel U, et al. Apoptosis is essential for neutrophil functional shutdown and determines tissue damage in experimental pneumococcal meningitis. PLoS Pathog. 2009;5(5):e1000461.

78. Hampson P, Hazeldine J, Lord JM. Neutrophil apoptosis and its induction as a potential treatment for chronic inflammatory disease. Curr Opin Hematol. 2013;20(1):10-15.

79. Kumar D, Moore RM, Mercer BM, Mansour JM, Redline RW, Moore JJ. The physiology of fetal membrane weakening and rupture: Insights gained from the determination of physical properties revisited. Placenta. 2016;42:59-73.

80. Regan JK, et al. Damage-Associated Molecular Pattern and Fetal Membrane Vascular Injury and Collagen Disorganization in Lipopolysaccharide-Induced Intra-amniotic Inflammation in Fetal Sheep. Reprod Sci. 2016;23(1):69-80.

81. Maymon E, et al. Human neutrophil collagenase (matrix metalloproteinase 8) in parturition, premature rupture of the membranes, and intrauterine infection. Am J Obstet Gynecol. 2000;183(1):94-99.

82. Sugimoto Y, et al. Failure of parturition in mice lacking the prostaglandin F receptor. Science. 1997;277(5326):681-683.

83. Ratajczak CK, Muglia LJ. Insights into parturition biology from genetically altered mice. Pediatr Res. 2008;64(6):581-589.

84. Chaturvedi V, et al. CXCR3 blockade protects against Listeria monocytogenes infection-induced fetal wastage. J Clin Invest. 2015;125(4):1713-1725.

85. Combs CA, et al. Amniotic fluid infection, inflammation, and colonization in preterm labor with intact membranes. Am J Obstet Gynecol. 2014;210(2):125.e1-125.e15.

86. Cappelletti M, et al. Type I interferons regulate susceptibility to inflammation-induced preterm birth. JCI Insight. 2017;2(5):e91288.

87. Bugl S, et al. Steady-state neutrophil homeostasis is dependent on TLR4/TRIF signaling. Blood. 2013;121(5):723-733.

88. Smith R. Parturition. N Engl J Med. 2007;356(3):271-283.

89. Subramaniam A, Abramovici A, Andrews WW, Tita AT. Antimicrobials for preterm birth prevention: an overview. Infect Dis Obstet Gynecol. 2012;2012:157159.

90. Chang Z, et al. Anakinra use during pregnancy in patients with cryopyrin-associated periodic syndromes (CAPS). Arthritis Rheu matol. 2014;66(11):3227-3232. 
91. Redline RW, et al. Amniotic infection syndrome: nosology and reproducibility of placental reaction patterns. Pediatr Dev Pathol. 2003;6(5):435-448. 